\title{
Behavioral medicine treatment for patients with chronic obstructive pulmonary disease
}

\author{
Tyler C. Bradstreet MS, Thomas J. Parkman BS
}

\section{INTRODUCTION}

Chronic obstructive pulmonary disease (COPD) is a debilitating respiratory disease characterized by progressive airflow limitation due to small airway disease, parenchymal destruction, and abnormal inflammatory responses in the lung. The primary symptoms of COPD include dyspnea (i.e., breathlessness), cough, and augmented sputum production. COPD is considered one of the most prevalent and debilitating diseases among adults, as it is associated with high levels of morbidity and mortality and a marked deterioration in health-related quality of life (HRQOL). ${ }^{2}$ The most common risk factor for developing COPD is cigarette smoking. Although COPD is not presently curable, the prognosis has improved over the last decade due to advances in medical treatment. ${ }^{3}$ Despite improvements in prognosis, COPD continues to have deleterious effects on patients' HRQOL due to medical and mental health comorbidities. ${ }^{4}$ Behavioral treatments can be a helpful adjunct in managing COPD and increasing HRQOL. ${ }^{5}$ The present article will discuss COPD's impact on patients' psychosocial functioning and describe behavioral treatments for managing COPD symptoms and increasing HRQOL.

\section{COPD: IMPACT ON PSYCHOSOCIAL FUNCTIONING}

COPD is not only physically limiting but also causes psychosocial deterioration. ${ }^{6}$ Research has identified direct physiological (i.e., inflammatory pro-

Cooresponding Author: Tyler C Bradstreet MS

Author Contact Information: tyler.bradstreet@ttu.edu

DOI: 10.12746/swrccc2016.0413.176 cesses due to stress) and indirect behavioral (i.e., poor disease management due to psychological symptoms) pathways linking psychosocial aspects with the course of COPD. ${ }^{2}$ Patients with COPD have psychiatric disorders at a greater rate than the general population. Sixty-five percent meet criteria for at least one disorder, with the rates of anxiety and depression disorders at $36 \%$ and $40 \%$, respectively. COPD patients report deficits in activities of daily living (ADLs), which lead to poorer HRQOL. Indeed, COPD patients encounter twice as many physically or mentally impaired days per month and are $70 \%$ more likely to encounter more than 14 unhealthy days per month than those without COPD.

\section{BehaVioral Health Treatments for COPD}

Providing COPD patients with the skills necessary to improve psychosocial functioning can moderate the course of illness and improve HRQOL. The following paragraphs will discuss specific behavioral treatments that can be used as adjunct therapies with routine care and will outline how clinicians can successfully implement each treatment with COPD patients.

Smoking Cessation. Given cigarettes' role in COPD, treatments aimed at smoking cessation are essential. If there is ambivalence about quitting, the use of motivational interviewing (MI) can help patients determine motivations to quit. Briefly, $\mathrm{Ml}$ is a focused and goal-directed method of intervention in which intrinsic motivation is facilitated to promote change. Motivational interviewing can be used to promote behavior change among patients by any health professional, such as pulmonologists or psychologists. 
Please see reference for Rollnick and colleagues' book for implementing $\mathrm{Ml}$ in healthcare settings. Next, it is important to set a specific and realistic quit date. Determine appropriate long-term (e.g., smokefree in 6 months) and short-term goals (e.g., reduce cigarettes used by 2 each week). Then, teach patients to become aware of personal smoking triggers, to develop healthy coping strategies for stress, and to use alternative behaviors to combat urges to smoke. Also, encourage patients to seek out support; quitting with someone or letting friends know the patients' goals increases the likelihood of success. ${ }^{10}$ Please view US Department of Health and Human Services reference for detailed protocols for quitting, helpful smartphone apps, and other informative smoking cessation tools. ${ }^{11}$

Chronic Pain Management. COPD symptoms can cause pain, which exacerbates ADL deficits and produces a poorer HRQOL. ${ }^{12}$ Chronic pain is highly prevalent in COPD patients ${ }^{13}$ with inflammation being the leading cause of neuropathic pain. ${ }^{14}$ In patients with COPD, the hyperinflation of the lung can exert pressure on the chest wall, spine, or diaphragm and cause significant pain; severe coughing and osteoporosis can also cause musculoskeletal symptoms. The preferred treatment for pain associated with this inflammatory response is pulmonary rehabilitation, which includes psychoeducation (e.g., understanding treatment plan, medications, diagnosis, and prognosis), breathing retraining, and strengthening chest wall muscles and the abdomen by aerobic exercise and resistance training. ${ }^{15}$ It can also be helpful to discuss the differences between acute and chronic pain with patients. Emotional support via psychotherapy or through close interpersonal relationships is imperative for managing chronic pain. ${ }^{16}$ Thus, pulmonary rehabilitation programs are doubly important for patients.

Cognitive Restructuring. The distress from COPD symptoms can be overwhelming and often leads to maladaptive thinking. Cognitive behavior therapy (CBT) can be used to help patients manage distress. ${ }^{17}$ CBT's underlying theory posits maladaptive thinking which influences mood and behavior and is common to all distress; it is not the situation in and of itself which determines what people feel, but rather how they construe the situation. For example, (1) when an event occurs (e.g., wheezing) and (2) causes an automatic thought (e.g., I'm going to die), the patient (3) emotionally interprets the event through that lens (e.g., fear; anxiety), which leads to a (4) maladaptive action (e.g., hyperventilation) validating the initial automatic thought. It is important to teach patients this underlying theory and then help them use cognitive restructuring to challenge automatic thoughts, which can lead to a more appropriate emotional reactions (e.g., I'm wheezing so I need to use my inhaler) and better outcomes in the management of distress and symptoms. Please view Beck Institute reference for additional information about how to help patients implement CBT-related skills for COPD. ${ }^{18}$

Relaxation Training. Breathing retraining, such as diaphragmatic breathing, involves contracting abdominal wall muscles during exhalation to assist in displacing the diaphragm upward. These can be helpful in pulmonary rehabilitation in COPD patients and can also be used to decrease general stress. ${ }^{19}$ Breathing retraining is used to restore normal diaphragm functioning, reduce likelihood of negative symptoms, and decrease the amount of work required to breathe. ${ }^{20}$ Additionally, interventions such as yoga, tai chi, progressive muscle relaxation, and distraction therapies have all produced significant improvements in COPD patients' forced expiratory volume (FEV1) and in depression, anxiety, and HRQOL.

Biofeedback Training. Biofeedback techniques can be helpful in reducing physical and psychological symptoms which limit patients with COPD in ADLs. ${ }^{21}$ Biofeedback is commonly used in combination with breathing retraining. It involves using strain gauge feedback from abdominal muscles and electromyogram (EMG) feedback from respiratory muscles of the chest wall to facilitate learning efficient diaphragmatic breathing. ${ }^{22}$ Biofeedback can lead to significant improvements in FEV1 in patients with COPD. ${ }^{23}$ Heart rate variability (HRV) biofeedback is also a helpful adjunctive treatment. ${ }^{22} \mathrm{HRV}$ at the frequency of respiration, which is synonymous with respiratory sinus arrhythmia (RSA), refers to the in- 
crease and decrease in heart rate with inspiration and expiration. Training patients to voluntarily increase RSA can improve autonomic control of cardiopulmonary function HRQOL of COPD patients. ${ }^{24}$

Physical Activity Counseling. Physical activity is essential for COPD patients; walking or cycling 2 hours/week is associated with a $30-40 \%$ reduction in respiratory mortality. ${ }^{25}$ Endurance and strength training can also improve skeletal muscle function and mitigate chronic pain, which improves treatment outcomes for COPD patients. ${ }^{26}$ Helping patients find motivation and determining specific exercise regimens are imperative, as lethargy is a strong predictor of mortality in COPD patients. ${ }^{27}$

Nutrition Counseling. Meeting nutritional guidelines can reduce the severity of respiratory symptoms; malnutrition often occurs in COPD patients. ${ }^{28}$ Furthermore, nutritional support that emphasizes essential nutrients, such as calcium, vitamin $D$, fiber, protein, and water, and seeks to limit consumption of fats, cholesterol, sodium, and foods that cause inflammation or are difficult to swallow or digest, should also be incorporated into diet plans. ${ }^{29}$ Ultimately, helping patients develop a consistent exercise and dietary regimen is important and encouraging patients to use self-monitoring techniques, such as keeping a daily log that can be reviewed. Also, as mentioned with smoking cessation, Ml techniques can help to address physical activity and nutrition concerns in patients with COPD.

\section{CONCLUSION}

This article provides an overview of interventions clinicians can use to better manage symptoms of patients with COPD and to improve their psychosocial functioning. While this list of interventions is not exhaustive, it describes the most frequently used behavioral interventions in these patients. There are several options to provide patients with information to utilize these skills. Psychologists and mental health counselors can provide this aspect of care. However, one concern might be the cost of additional treat- ments for patients; traditional psychotherapy costs vary and depend upon whether they are master's level or doctoral level clinicians, and whether their services are covered by health insurance. In integrated health systems behavioral medicine interventions can be included in the patient's appointment at no additional cost. For example, if a COPD patient attends an appointment and the patient could benefit from cognitive restructuring, the pulmonologist could contact the psychologist and have a "warm hand-off," in which the pulmonologist introduces the psychologist and has the psychologist implement the intervention for 15-30 minutes with no change in cost. Additionally, if appointment length (or cost) is an issue, group meetings based on these interventions at other times could be provided. Alternatively, if a psychologist or mental/behavioral health clinician is not available, other health professionals, such as nurses, allied health professionals, or physicians, could be trained in these interventions. Ideally, regardless of who works with patients on these techniques, all personnel should have a basic understanding of these behavioral treatments. Ultimately, the best strategies for implementation may depend on existing clinic procedure, access to resources, availability of interdisciplinary team members, and time allotted to appointments for each patient. What need not vary, however, is the use of these treatments for COPD as an adjunct to pharmacological treatments, as both approaches can improve the patient's HRQOL.

\footnotetext{
Author Affiliation: Tyler C Bradstreet and Thomas J Parkman are graduate students in psychology at Texas Tech University in Lubbock, TX.

Received: $12 / 16 / 2015$

Accepted: 01/10/2016

Reviewers: Olusegun Oyenuga MD

Published electronically: 01/15/2016

Conflict of Interest Disclosures: None
} 


\section{REFERENCES}

1. Global Initiative for Chronic Obstruct Lung Disease (GOLD). Global strategy for diagnosis, management, and prevention of COPD 2010. Available from: http://www.goldcopd.com

2. World Health Organization. Global surveillance, prevention, and control of chronic respiratory diseases: A comprehensive approach. Geneva, Switzerland: World Health Organization 2007. Available from: http://whqlibdoc.who.int/ publications/2007/9789241563468_eng.pdf.

3. Almagro P, Castro A. Helping COPD patients change health behavior in order to improve their quality of life. International Journal of COPD 2013; 8, 335-345.

4. von Leupoldt A, Fritzsche A, Trueba AF, Meuret AE, Ritz T. Behavioral medicine approaches to chronic obstructive pulmonary disease. Annals of Behavioral Medicine 2012; 44, 52-65.

5. National Institute of Health: National Heart, Lung, \& Blood Institute. Health information for the public: What is COPD? 2015. Available from:

http://www.nhlbi.nih.gov/health/health-topics/topics/copd.

6. Maurer J, Rebbapragada V, Borson S, Goldstein R, Kunik ME, Johannes AM, et al. Anxiety and depression in COPD: Current understanding, unanswered questions, and research needs. Chest 2008; 134, 43S-56S.

7. Yohannes AM, Willgoss TG. The accuracy of the anxiety inventory respiratory disease scale for patients with chronic obstructive pulmonary disease. International J Geriatric Psychiatry 2015; 30, 106-108.

8. Brown DW, Pleasants R, Ohar JA, Kraft M, Donohue JF, Mannino DM, et al. Health-related quality of life and chronic obstructive pulmonary disease in North Carolina. North American J Med Sci 2010; 2, 60-65.

9. Rollnick S, Miller WR, Bulter CC. Motivational interviewing in health care: Helping patients change behavior: Applications of motivational interviewing 2008. New York: Guilford Press.

10. Hughes JR. Motivating and helping smokers to stop smoking. J General Internal Medicine 2003; 18, 1053-1057.

11. U.S. Department of Health and Human Services. Have you built a quit plan? 2015. Retrieved from: http://smokefree.gov/

12. Lee AL, Harrison SL, Goldstein RS, Brooks D. Pain and its clinical associations in individuals with COPD: A systematic review Chest. 2015; 147, 1246-1258.

13. Roberts MH, Mapel DW, Hartry A, Von Worley A, Thomson

H. Chronic pain and pain medication use in chronic obstructive pulmonary disease. A cross-sectional study. Annals Am Thoracic Soc 2013; 10, 290-298.

14. van Dam van Isselt EF, Groenewegen-Sipkema KH, Spruitvan Eijk M, Chavannes NH, de Waal MM, Janssen DA, Achterberg WP. Pain in patients with COPD: A systematic review and meta-analysis. BMJ Open 2015; 4, 1-17.
15. Kon SC, Dilaver D, Mittal M, Nolan CM, Clark AL, Canavan $\mathrm{JL}$, et al. The Clinical COPD Questionnaire: Response to pulmonary rehabilitation and minimal clinically important difference. Thorax 2014; 69, 793-798.

16. Gabriel R, Figueiredo D, Jácome C, Cruz J, Marques A. Dayto-day living with severe chronic obstructive pulmonary disease: towards a family-based approach to the illness impacts. Psychology \& Health 2014; 29, 967-983.

17. Beck JS. Cognitive behavior therapy: Basics and Beyond 2011. New York: Guilford Press.

18. Beck Institute. Cognitive Behavior Therapy. Retrieved from: http://www.beckinstitute.org/

19. Beauchamp MK, Janaudis-Ferreira T, Goldstein RS, Brooks D. Optimal duration of pulmonary rehabilitation for individuals with chronic obstructive pulmonary disease: A systematic review. Chronic Respiratory Diseases 2011; 8, 129-140.

20. Faling LJ. Pulmonary rehabilitation--physical modalities. Clinics in chest medicine 1986; 7, 599-618.

21. Volpato E, Banfi P, Rogers SM, Pagnini F. Relaxation techniques for people with chronic obstructive pulmonary disease: A systematic review and a meta-analysis. Evidence-Based Complementary and Alternative Medicine 2015; 1-22.

22. Giardino ND, Chan L, Borson S. Combined heart rate variability and pulse oximetry biofeedback for chronic obstructive pulmonary disease: preliminary findings. Applied Psychophysiology and Biofeedback 2004; 29, 121-133.

23. Estève F, Blanc-Gras N, Gallego J, Benchetrit G. The effects of breathing pattern training on ventilatory function in patients with COPD. Biofeedback and Self-Regulation 1996; 21, 311-321. 24. Lehrer PM, Vaschillo E, Vaschillo B. Resonant frequency biofeedback training to increase cardiac variability: Rationale and manual for training. Applied Psychophysiology and Biofeedback 2000; 25, 177-191.

25. Garcia-Aymerich J, Lange $P$, Benet M, Schnohr P, Antó JM. Regular physical activity reduces hospital admission and mortality in chronic obstructive pulmonary disease: a population based cohort study. Thorax 2006; 6, 772-778.

26. Gimeno-Santos E, Frei A, Steurer-Stey C, de Batlle J, Rabinovich RA, Raste Y, Kulich K. Determinants and outcomes of physical activity in patients with COPD: a systematic review. Thorax 2014; 69, 731-739.

27. Waschki B, Kirsten A, Holz O, Müller KC, Meyer T, Watz $\mathrm{H}$, Magnussen $\mathrm{H}$. Physical activity is the strongest predictor of all-cause mortality in patients with COPD: a prospective cohort study. Chest 2011; 140, 331-342.

28. Ezzell L, Jensen GL. Malnutrition in chronic obstructive pulmonary disease. Am J Clinical Nutrition 2000; 72, 1415-1416.

29. Collins PF, Stratton RJ, Elia M. Nutritional support in chronic obstructive pulmonary disease: a systematic review and metaanalysis. Am J Clinical Nutrition 2012; 95, 1385-1395. 